\title{
System for Start of Internal Combustion Engine with Hybrid Battery-Supercapacitor Source
}

\author{
Kaspars Kroics (Scientific Assistant, Riga Technical University Cesis Branch)
}

\begin{abstract}
The supercapacitors are electrical energy storage devices with high power density, low series resistance and they can be charged and discharged millions of times. That makes supercapacitors as promising solution for application in the starting process of the internal combustion engines (ICE). In the paper application of the small capacity ultracapacitor bank with DC-DC converter is analyzed for the ICE starting. The starting process of the ICE is analyzed more delicate to understand starting time and energy. A prototype is designed and tested under real conditions. Experimental results are registered and included in the paper.
\end{abstract}

Keywords - Supercapacitor, internal combustion engine, engine starting, lead-acid batteries.

\section{INTRODUCTION}

To make ICE start it must be turned at some speed, so that it sucks fuel and air into the cylinders, and compresses it. Usually the starting system converts electrical energy from the lead-acid batteries into mechanical energy to turn the engine over. The main components of the starting system shown in Fig. 1 are: the ignition switch or start button, the starter solenoid, the starter motor and the battery.

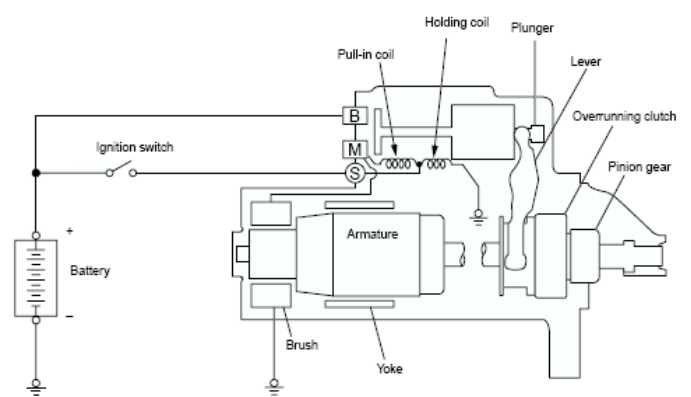

Fig. 1. Classical starting system of the ICE

When the key is turned in the ignition switch to the start position, electricity flows from the battery to the starter solenoid. When coils of the solenoid are energized by electricity, they create a magnetic field which attracts and pulls a plunger with an iron rod. Attached to one end of this plunger is a shift lever. The lever is connected to the drive pinion and clutch assembly of the starter motor. The movement of the rod closes two heavy contacts, completing the circuit from the battery to the starter.

The rod also has a return spring - when the ignition switch stops feeding current to the solenoid, the contacts open and the starter motor stops. The starter motor is a small but powerful DC brushed electric motor that delivers a high degree of power for a short period of time. When the starter motor is energized it engages the flywheel ring gear and produces torque, which turns the flywheel and cranks the engine.

The improvement of the start system with the supercapacitor allows the use of old batteries which are unable to provide enough power to start the ICE but have energy to charge ultracapacitor with low current. It reduces high discharge currents from lead-acid battery thus prolonging lifetime of the lead-acid battery 2-3 times [1]. Some forecasts expect that start-stop system that allows switching off the ICE during the short time stops to be included on more than half of a new ICE vehicles. In such system lead-acid starter batteries that enable the system to restart the engine many times per day may need to be replaced more frequently therefore demand for new technology that solves this problem is big. Moreover, battery-ultracapacitor hybrid reduces the volume of the storage device by $30 \%$ and reduces weight by $25-40 \%$ [2], [3], [4].

The battery-ultracapacitor hybrid can be passive [3], [5], semi active [7], [2] and fully active [8], [9], [10]. In the passive topology, the lead-acid battery and supercapacitor are connected parallel without any converter. Although this hybrid is the cheapest the whole energy of the supercapacitor can not be used. The fully active topology attains the best performance and often is used in hybrid cars but in this case it requires bulky, expensive DC-DC converter for big current. This paper presents approach based on low power DC-DC converter used for charging of the ultracapacitor.

\section{THE START OF THE ICE}

To study of ICE starting process, it was used a hall-effect based current sensor HTFS 200-P with maximum current 300 A and Fluke 199C oscilloscope. The measurements performed on two passenger cars - Skoda Octavia with 1.8 petrol engine and Toyota Corolla with 2.0 diesel engine.

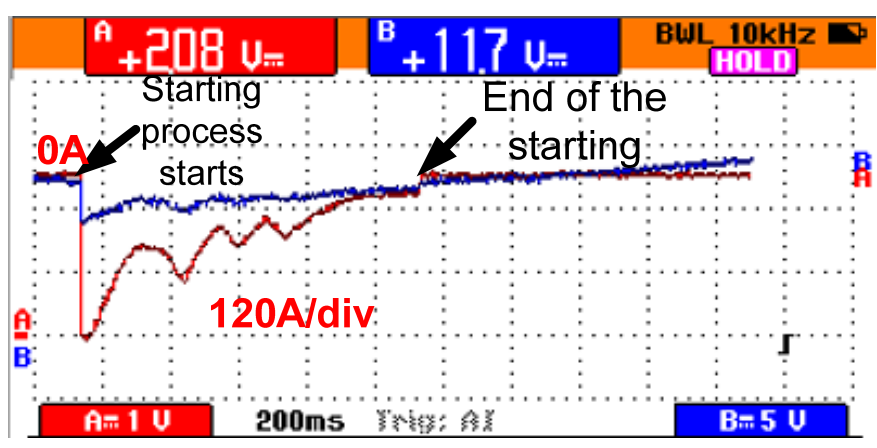

Fig. 2. Typical current and voltage profile of the starting process 
Figure 2 shows typical current and voltage profile of the starting process. The current is bigger in case of diesel engine, if the ambient temperature is lower, in the same way engine type, starter motor type, maintenance conditions, oil viscosity, ignition quality and other factors affect starting current but anyway current profile trend stays similar to the shown in figure. The characteristic starter operation modes are short circuit mode in which rotation speed of the starter motor is close to zero, the current and torque is maximum and load mode in which engine starts to rotate, current decreases. The period with big current lasts about $50 \mathrm{~ms}$. The ripples in the current are due to the compression and expansion of the engine pistons.

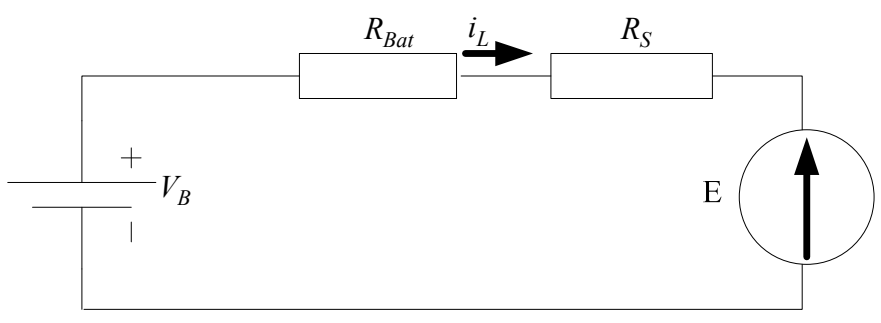

Fig. 3. Simple equivalent circuit of ICE starting system

Starting system (Fig. 3) can be represented by the following equations:

$$
\begin{gathered}
V_{B}=\left(R_{B a t}+R_{S}\right) i_{L}+E \\
J \frac{d \omega}{d t}=T_{e l}-T_{\text {load }} \\
E=c_{M} \omega \\
T_{e l}=c_{M} i,
\end{gathered}
$$

where $V_{B}$ - no load voltage of the battery, $E$ - the back electromotive force, $R_{S}$ - the stator resistance, $R_{B a t}$ - internal resistance of the battery, $i_{L}$ - start current, $\mathrm{J}$ - momentum of inertia of all rotating parts, $c_{M}$ - the torque constant, $\omega$ - the angular speed.

To start an ICE, the motor must be accelerated to some speed $\omega_{0}$. From equation 3 follows that in that case $E_{0}$ will be the greatest. By rearranging of Eq. 1:

$$
i_{L 0}=\frac{V_{B}-E_{0}}{R_{B a t}+R_{S}} .
$$

From Eq. 5 can be concluded that if state of charge or state of health of lead-acid battery is low then $V_{B}$ is lower but $\mathrm{R}_{\mathrm{Bat}}$ greater than usual therefore current $\mathrm{i}_{\mathrm{L} 0}$ can be to small for developing sufficient torque (Eq. 4) to overcame load torque $\mathrm{T}_{\text {load }}$ for accelerating engine to the start speed $\omega_{0}$ (Eq. 2). Such battery is not valid for ICE starting and must be charged or replaced.

Although weak battery produces lower torque during first moment it is not critical for ICE starting only the starting process will be a little bit longer. The very high short circuit current in the first moment of the starting process drastically affects state of the health of the batteries. Lead acid batteries operate best at constant power levels.
Reducing this spike from the battery in a starting circuit can increase the life of the battery, because the stress on it will be less as the starter is first engaged. The idea presented in the paper is reduce this current spike by means of supercapacitor to increase lifetime of lead-acid starting battery.

The overcurrent during short circuit mode of the starter motor cause the battery voltage unstable and its voltage falls to unacceptable level (Fig. 2). This voltage drop can generate the malfunction of the devices connected to the battery (radio, electronic control unit, etc). In Fig. 2 is shown the battery voltage during the starting process in summer with charged battery but anyway the voltage drops below $9 \mathrm{~V}$ (the normal limit). The problem of the voltage drop during starting is more important in vehicles with the start stop function while the frequency of engine start is much higher than in a conventional cars and could endanger the users by resetting systems that must be interruptible.

One of the solution to prevent voltage drop is to use two batteries [11]: one to start the engine and other for the supply the electrical systems. Other solution is to use 6 super-capacitor in series in parallel to the battery to supply the power necessary to start the engine [3], [12]. The supercapcaitors used for such application must be with big capacity, it means additional price and volume required. Another solution is the DC-DC converter [13] but it is bulky and expensive for such high level currents or linear voltage stabilization system proposed in [14] but such system has additional energy losses. In the paper proposed system allows to stabilize the battery voltage during short circuit mode.

\section{THE HARDWARE OF THE SYSTEM}

The proposed system for ICE starting is based on series connection of the supercapacitors and the DC-DC converter (Fig. 4.). The supercapacitor based energy storage is charged through the converter with low current. During starting process of the ICE energy is taken from the supercapacitors as a result the lead acid battery is not damaged with short circuit current, increases lifetime of the battery, the supply voltage of the vehicle electronics stays constant during the starting process.

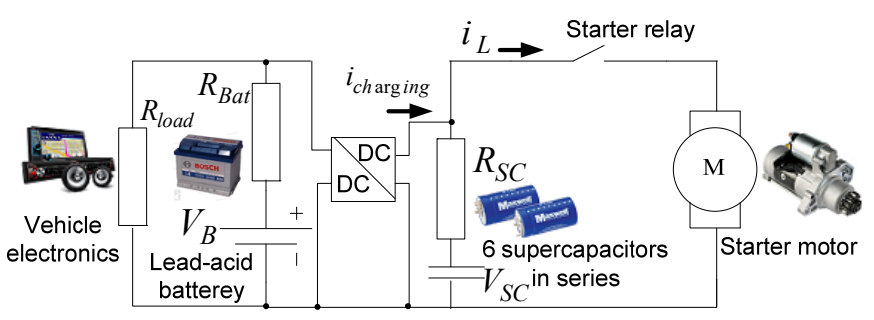

Fig. 4. The proposed starting system of the ICE

\section{A. Selection of the supercapacitors}

The supercapacitors are selected as cheap as possible but with internal resistance at least equal to the lead acid battery 
or lower. Taking these principles into account BCAP0350 E270 T11 supercapacitors with the capacity of $350 \mathrm{~F}$ are selected. In the datasheet [15] only maximum internal resistance is specified and is equal to $3,2 \mathrm{~m} \Omega$. To ensure that the real internal resistance is below this value short circuit experiment was carried out.

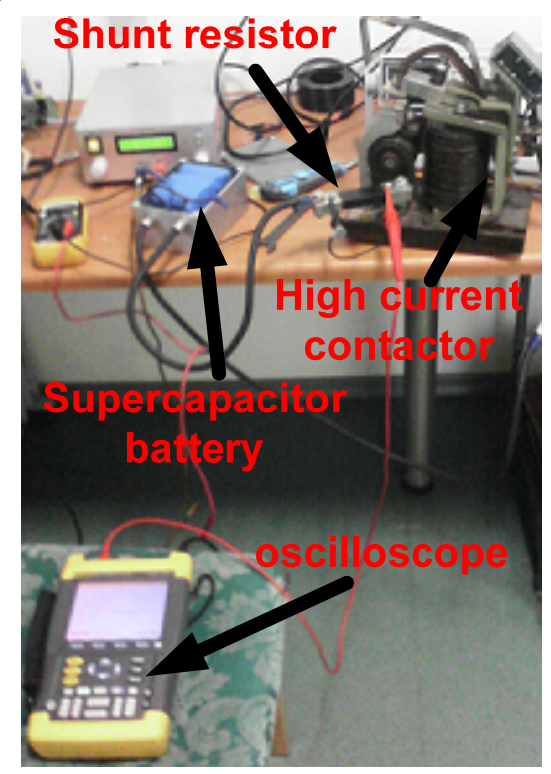

Fig. 5. Experimental setup of the short circuit test

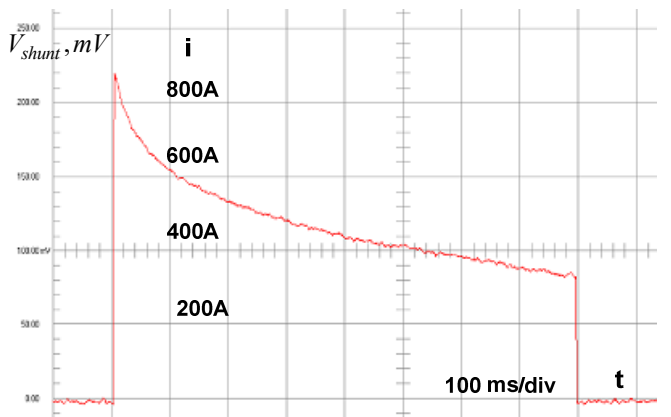

Fig. 6. Current during the short circuit test

Fig. 5. shows experimental setup of the short circuit test. The ultracapacitors was charged to 15 volts, connected to the shunt resistor through high current contactor. The contactor was activated and voltage on shunt resistor was measured with oscilloscope. In the pike current reaches 880 A (Fig. 6.), it means that internal resistance of one supercapacitor is approximately equal to $2,8 \mathrm{~m} \Omega$ and to 17 $\mathrm{m} \Omega$ for series connection of the six cells respectively. This value is close to the internal resistance of the lead-acid starting battery and therefore suitable for ICE starting.

\section{B. The DC-DC converter}

The nominal voltage of the supercapacitor series is equal to the 15 volts but in discharge process the voltage can drop below 10 volts. Input voltage of the DC-DC converter according to state of charge of the lead-acid batterey can be in range from 10 to 13 volts, when generator is working voltage is in range from 14 to 15 volts. So for such application buck-boost topology must be used. The LTC3780 is a high performance buck-boost switching regulator controller that operates from input voltages above, below or equal to the output voltage. The constant frequency current mode architecture allows to use frequency of $400 \mathrm{kHz}$. With a wide $4 \mathrm{~V}$ to $30 \mathrm{~V}(36 \mathrm{~V}$ maximum) input and output range and seamless transfers between operating modes, the LTC3780 is suitable for particular application.

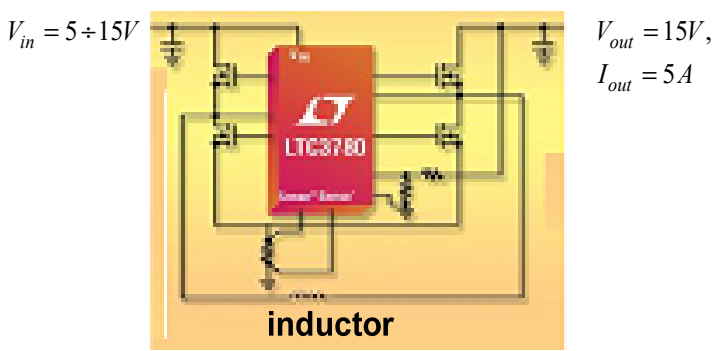

Fig. 7. Simplified diagram of the DC-DC converter based on LTC3780 [16]

The LTC3780 integral circuit requires four external Nchannel power MOSFETs (Fig. 7.), two for the top switches and two for the bottom switches. The Schottky diodes in parallel to the MOSFETs are connected to conduct during the dead time between the conduction of the power MOSFET switches. The Shottky diodes significantly reduces reverse recovery current between one switch turnoff and other switch turn-on, which improves converter efficiency and reduces voltage stress on switches.

The inductor value has a direct effect on ripple current. The inductor current ripple $\Delta \mathrm{I}$ is set to $20 \%$ of the maximum inductor current. For a given ripple the inductance terms in continuous mode are as follows [16]:

$$
\begin{aligned}
& L_{\text {boost_min }}=\frac{V_{\text {in }(\min )}^{2} \cdot\left(V_{\text {out }}-V_{\text {in }(\min )}\right) \cdot 100}{f \cdot I_{\text {out }(\max )} \cdot \Delta I(\%) \cdot V_{\text {out }}^{2}} \\
& L_{\text {buck_min }}=\frac{V_{\text {out }(\min )} \cdot\left(V_{\text {in }(\max )}-V_{\text {out }(\min )}\right) \cdot 100}{f \cdot I_{\text {out }(\max )} \cdot \Delta I(\%) \cdot V_{\text {in }(\max )}},
\end{aligned}
$$

where $\mathrm{f}$ is operating frequency in $\mathrm{Hz}, \Delta \mathrm{I}(\%)$ is allowable inductor current ripple, $\mathrm{V}_{\mathrm{in}(\min )}$ is minimum input voltage, $\mathrm{V}_{\text {in(max) }}$ is maximum input voltage, $\mathrm{V}_{\text {out }}$ is output voltage, $I_{\text {out(max) }}$ is maximum output load current. The value of the minimum inductor calculated by (6) and (7) is $4 \mu \mathrm{H}$. Inductor with inductance $20 \mu \mathrm{H}$ with toroidal molypermalloy core from electronic part catalog was selected.

\section{The test of the system}

To test the starting system with supercapacitor battery the prototype was built to test it during the starting process of the ICE. Fig. 8. shows prototype of the device, it has size $150 \mathrm{~mm} \times 110 \mathrm{~mm} \times 8 \mathrm{~mm}$. The prototype was installed on the vehicle and tested month long. It works without problems. With one charging of the supercapacitors the ICE can be 
started 2-4 times but the test was performed in summer and with vehicle equipped with petrol engine.

The energy stored in supercapacitors is to little to start ICE 3 times surely in any conditions. Such engine start module has enough energy only for petrol cars with small ICE. Figure 9. shows voltage of the supercapacitor battery and current during starting process.
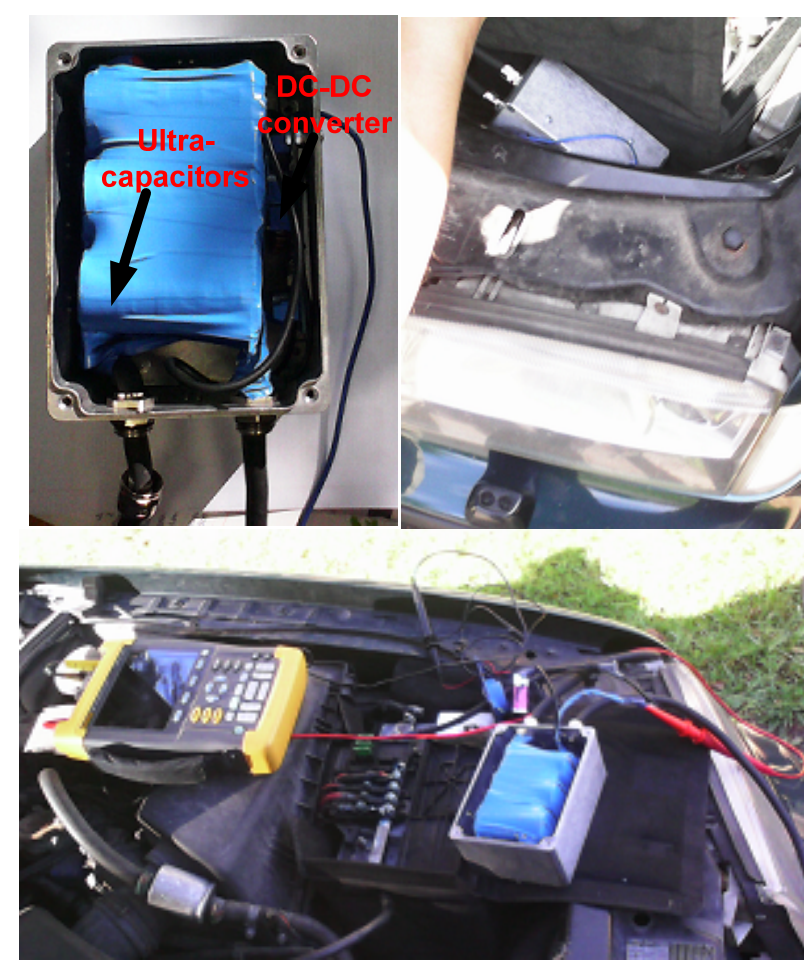

Fig. 8. Prototype device for starting of the ICE; device installed in the vehicle; measuring of supercapacitor voltage and start current during starting process

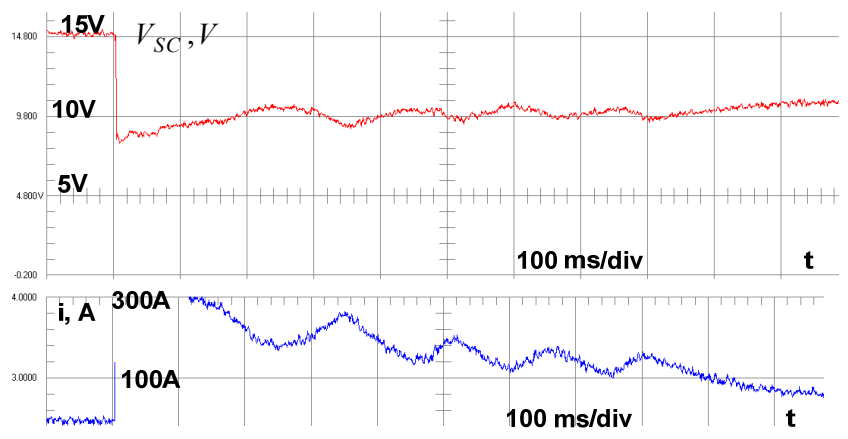

Fig. 9. Voltage of supercapacitors and current during provides required current for starting of the ICE but voltage the starting process

Figure 9 shows that energy storage oscillogram shows that voltage of the ultracapacitor goes down fast, it means that energy of the supercapacitors are consumed to start ICE and in low ambient temperature the energy will be consumed so fast that starting of the ICE becomes impossible.

\section{THE IMPROVED SYSTEM}

As supercapacitors with higher capacity significantly increase costs of the system it is necessary to find way to remove current spikes from lead-acid battery. The MOSFET transistors with low breakdown voltage is cheap and with low on state resistance. The parallel connection of several MOSFETs can commutate starting current for short time without heating up. In [17] it is proposed structure for application in a hybrid vehicle in which the ultracapacitor bank and the battery bank are connected to the DC bus via a controlled switch and a bi-directional DC-DC converter is placed between the UC bank and the battery bank. This idea can be adapted to the ICE starting system.

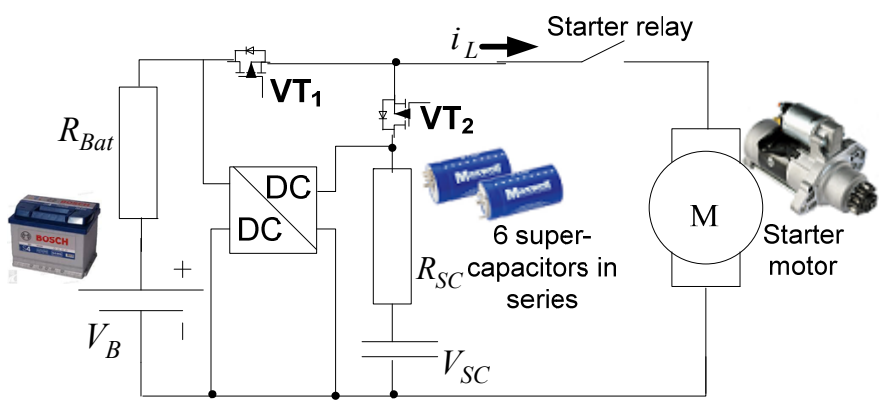

Fig. 10. ICE starting system with MOSFET switches

Figure 10 shows ICE starting system complemented with two controllable switches. The ultracapacitor through MOSFET $\mathrm{VT}_{2}$ is connected to the starter but lead-acid battery through $\mathrm{VT}_{1}$ is connected to the starter. When the starter relay closes the main contact, switch $\mathrm{VT}_{2}$ is turned on, short circuit current goes from supercapacitor to the starter motor. After typical short circuit time (approximately equal to $150 \mathrm{~ms}$ ) or by detecting recovery of the voltage switch $\mathrm{VT}_{2}$ is turned off and switch $\mathrm{VT}_{1}$ is turned on. The power to crank engine goes new from the lead-acid battery. From the voltage pulsations during cranking rotation speed can be detected. If this speed is analyzed than can be detected speed loss of the starter motor (internal resistance of lead acid battery is to high or voltage to low to start ICE) and $\mathrm{VT}_{2}$ can be switched on to supply energy to engine starting from both sources.

\section{V.CONCLUSIONS}

In the paper supercapacitor based portable device was described for the ICE starting. The supercapacitor based power source is charged at low rate from the battery and then releases charge at rate required for proper starting of the ICE. The device allows to remove high current load from the lead-acid battery thus increasing lifetime of the battery in the same time it allows to avoid the voltage drop during the starting process.

Device prototype was designed and tested on the vehicle. The energy of the $350 \mathrm{~F}$ supercapacitor module can be not enough for the whole starting process therefore it is proposed to use of MOSFETs to connect module only during short circuit time. This system requires further practical implementation and testing. 


\section{REFERENCES}

[1] A.W. Stienecker, T. Stuart and C. Ashtiani, "A combined ultracapacitor-lead acid battery storage system for mild hybrid electric vehicles," 2005 IEEE Conference Vehicle Power and Propulsion, pp. 350-355, 2005.

[2] C. Lerman, A. Horosov, A. Kuperman, "Capacitor semi-active battery-ultracapacitor hybrid energy source," 2012 IEEE 27th Convention Electrical \& Electronics Engineers in Israel, pp.1-4, 1417 Nov. 2012.

[3] R.A. Dougal, L. Shengyi, R.E. White "Power and life extension of battery-ultracapacitor hybrids," Components and Packaging Technologies, IEEE Transactions on , vol. 25, no.1, pp.120-131, Mar 2002.

[4] W. Henson "Optimal battery/ultracapacitor storage combination," Journal of Power Sources, vol. 17, no.1, pp. 417-423, 2008.

[5] J.P. Zheng, T.R. Jow, M.S. Ding, "Hybrid power sources for pulsed current applications," Aerospace and Electronic Systems, IEEE Transactions on , vol.37, no.1, pp.288-292, Jan 2001.

[6] G. Lijun, R.A. Dougal, and L. Shengyi, "Power enhancement of an actively controlled battery/ultracapacitor hybrid," Power Electronics, IEEE Transactions on , vol.20, no.1, pp.236-243, Jan. 2005.

[7] L. Solero, A. Lidozzi, J.A. Pomilio, "Design of multiple-input power converter for hybrid vehicles," Power Electronics, IEEE Transactions on , vol.20, no.5, pp.1007-1016, Sept. 2005

[8] A. F. Burke, "Batteries and ultracapacitors for electric, hybrid, and fuel cell vehicles," Proc. IEEE, vol. 95, no. 4, pp. 806 -820, 2007.

[9] J. M. Blanes, R. Gutierrez, A. Garrigs, J. L. Lizan and J. Martinez, "Electric vehicle battery life extension using ultracapacitors and a FPGA controlled interleaved buck-boost converter," IEEE Transactions of Power Electronics., vol. 28, no. 12, pp.5940-5948, 2013.

[10] P. Concha, P. Velez, M. Lafoz, J.R. Arribas, "Flexible low-cost system to test batteries and ultracapacitors for electric and hybrid vehicles in real working conditions," Electric Vehicle Symposium and Exhibition (EVS27), pp.1-11, 17-20 Nov. 2013.
[11] J.B. Olson, E.D. Sexton, "Operation of lead-acid batteries for HEV applications", Battery Conference on Applications and Advances, pp. 205-210, 11-14 Jan. 2000.

[12] B. Lee, D.-H. Shin, H.-S. Song, H. Heo and H.-J. Kim, "Development of an advanced hybrid energy storage system for hybrid electric vehicles." Journal of Power Electronics vol. 9, no. 1, pp. 51-60, 2009.

[13] N. Muntean, O. Cornea, O. Pelan, C. Lascu, "Comparative evaluation of buck and hybrid buck DC-DC converters for automotive applications," 15th International Power Electronics and Motion Control Conference (EPE/PEMC), pp. DS2b.3-1 - DS2b.3-6, 4-6 Sept. 2012.

[14] G. Chiappori, P. Le Moigne, P. Delarue, M. Chemin, "Voltage stabilization System for Stop - Start Vehicles: Systemic Approach," IEEE Vehicle Power and Propulsion Conference (VPPC), pp.1-6, 27-30 Oct. 2014.

[15] "BC series ultracapacitors datasheet". [Online]. Available: http://www.maxwell.com/images/documents/bcseries_ds_10171054.pdf [Accessed: Aug. 3, 2015].

[16] "LTC3780 datasheet". [Online]. Available: http://cds.linear.com/docs/en/datasheet/3780ff.pdf. [Accessed: Aug. $1,2015]$.

[17] C. Xiang, Y. Wang, S. Hu, and W. Wang, "A new topology and control strategy for a hybrid battery-ultracapacitor energy storage system," Energies, vol. 7, no. 5, pp. 2874-2896, Apr. 2014.

Kaspars Kroics received his BSc and MSc degrees in electrical engineering from Riga Technical University, Riga, Latvia, in 2006 and 2008 respectively. Currently he is $\mathrm{PhD}$ student at Riga Technical University.

From 2009 to 2012 he was an electronic device engineer at Arcus Elektronika Ltd. He is presently a research assistant in the Laboratory of Power Electronic at the Institute of Physical Energetic. His main research interest are switch mode power converters, digital control of power electronic, applied design of power converters and control systems. Phone: +371 26103547, e-mail: kaselt@inbox.lv. 